\title{
Alignment versus sonority in CCC structures: a paradigmatic explanation
}

\begin{abstract}
In the present analysis, we argue that the canonical difference between Moroccan Arabic triliteral nouns and verbs can be explained by invoking the active role of an alignment and a sonority condition constraint. We attempt to clarify the issue by arguing that an examination of the perfective inflectional paradigm of sound triliteral verbs can provide hints about the difference in behavior exhibited by CCC verbs and nouns. Our analysis, couched within Optimality Theory (McCarthy and Prince 1993a, Prince and Smolensky 1993), also revises the treatment of the Moroccan Arabic triliteral sound verb within Optimal Paradigms Theory (McCarthy 2005), which suggests that the structure of triliteral sound stems is the result of "majority- rules effects". The rationale behind our research is to demonstrate that triliteral verbs fail to satisfy the sonority condition because of phonological and paradigmatic reasons and to point to the necessity of incorporating a paradigmatic contrast constraint in the analysis.
\end{abstract}

Keywords: sonority, alignment, schwa epenthesis, Optimal Paradigms, perfective inflection, Moroccan Arabic.

The canonical difference between monosyllabic CCC nouns and verbs is one of the most documented aspects in Moroccan Arabic (MA) morpho-phonology (Harrell 1968, Benhallam 1990a, Bennis 1992, Boudlal 2001, McCarthy 2005, Bernouss 2007b, among many others). Whereas verbs adopt exclusively a $\mathrm{CC} \partial \mathrm{C}$ form, nouns have both $\mathrm{CC} \partial \mathrm{C}$ and $\mathrm{C} ə \mathrm{CC}$ patterns. We argue that this basic difference can be accounted for by having recourse to two crucial constraints: an alignment constraint (Align-R. [Verb]), which stipulates that syllables must 
coincide with the right edge of the verb stem, and a sonority condition constraint (SonCond.), which fixes the place of the epenthetic schwa in nouns before the most sonorant consonant or between the last two consonants with the same sonority index. The study, couched within Optimality Theory (OT) (McCarthy and Prince 1993a, Prince and Smolensky 1993), is also an attempt to provide an alternative to the analysis of McCarthy (2005), where he argues that the structure of the MA triliteral sound stem is the result of majority-rules effects. Specifically, we suggest that the sonority condition is not satisfied in verbs because of phonological and paradigmatic reasons (related to the perfective inflectional paradigm of sound triliteral verbs); thus, one needs to refer to inflectional paradigms to explain derivational phenomena. In this respect, we argue in favor of the existence of a paradigmatic contrast constraint that is not subsumed under the usual OT faithfulness and markedness families.

\section{CCəC Versus $\mathrm{CəCC} / \mathrm{CC} \mathrm{C}^{1}$ patterns}

The problem we address has to do with the canonical difference between sound triliteral verbs and triliteral nouns. This formal difference, which involves an interesting interaction between syllabification and schwa epenthesis, reveals a unique property of MA phonology. In monosyllabic words, the epenthetic site varies from verbs to nouns: whereas the schwa is inserted invariably between the last two consonants in verbs $(\mathrm{CC} \partial \mathrm{C})$, it is inserted before the most sonorous consonant or between the last two consonants with the same sonority index in nouns.

(1)

Verbs:

$\mathrm{CCəC}$

\footnotetext{
${ }^{1}$ In MA, schwa syllables have the following characteristics: prevocalic segments are maximally bisegmental; the number of postvocalic segments varies from one to two segments; and these syllables are always close (Bernouss 2007b).
} 
[ktəb] 'to write', [lbəs] 'to wear clothes' [Dkər] $]^{2}$ 'to mention', [Krəh] 'to hate', [dlək] 'to make a massage'.

\section{Nouns:}

\section{$\mathrm{A}-\mathrm{Cə} \boldsymbol{} \mathrm{CC}$}

[bənt] 'a girl', [wəld] 'a boy', [fərg] 'a group', [qərd] 'a monkey'.

\section{B- $\mathrm{CCəC}$}

[wdən] 'an ear', [kfən] 'shroud', [Dfər] 'a nail', [ktəf ]'a shoulder' , [Sfər] 'traveling', [Rməl] 'sand', [smən] 'salty butter'.

Alghadi (1990) has captured the linguistically significant generalization whereby this category of nouns includes a schwa that is sensitive to the sonority of the last two consonants. For the author, in trisegmental nouns, the schwa is epenthesized in the following environments:

(2) a. $\mathrm{C}_{1} \partial \mathrm{C}_{2} \mathrm{C}_{3}$ if $\mathrm{C}_{2}$ is more sonorous than $\mathrm{C}_{3}$.

b. $\mathrm{C}_{1} \mathrm{C}_{2} \partial \mathrm{C}_{3}$ if $\mathrm{C}_{3}$ is more sonorous than $\mathrm{C}_{2}$ or if $\mathrm{C}_{2}$ and $\mathrm{C}_{3}$ are equal in sonority.

The research question we try to answer has to do with the reason behind the behavior of triliteral sound verbs, which constantly satisfy right-alignment at the detriment of the sonority condition (the final syllable is invariably aligned with the stem at the right periphery). In the next section, we will describe the difference between $\mathrm{CCC}$ verbs and nouns within OT, and in section 2 we provide an explanation for the recurrent sonority violation by verbs and refute the treatment of the triliteral sound stem within the Optimal Paradigms (OP) model as exposed by McCarthy (2005).

Among the constraints that are responsible for the regulation of MA word structure, there are two crucial ones. The first one is a constraint that parses segments in syllables (Prince and Smolensky 1993).

\footnotetext{
${ }^{2}$ Emphatic consonants are represented by capital letters.
} 
(3) PARSE-segment (Parse-seg.)

Segments are parsed in syllables ${ }^{3}$

The second constraint, named ${ }^{*}$ Compl, prohibits complex margins from emerging as optimal:

(4) *Compl (Prince and Smolensky 1993)

Complex onsets and codas are prohibited.

In addition to the above constraints, there are $* \mathrm{P} / \mathrm{C}$ and Nucleus (Prince and Smolensky 1993):

(5) $* \mathrm{P} / \mathrm{C}$

C may not associate to Peak (Nuc) nodes.

(6) Nucleus (N)

A syllable must have a nucleus.

Whereas Parse, *P/C, and $\mathrm{N}$ triggers epenthesis through Dep-IO violation (schwa insertion) when consonants are not part of any syllable ${ }^{4}{ }^{*}$ Compl. dismisses complex margins by giving the first element of an onset and the second element of a coda the status of an appendix through *Ap. violation.

(7) *Ap. (Sherer 1994)

Appendices are not allowed

Beside the above constraints that are active across the whole language, there is an alignment constraint (Align-R. [Verb]), which aligns the sound verb stem with final syllables at the right periphery. The alignment constraint is crucial to the regulation of the MA lexicon as it differentiates between sound triliteral verb stems which incorporate a schwa invariably between the last two root consonants $(\mathrm{CC} \partial \mathrm{C})$, and triliteral nouns where schwa insertion is governed by the sonority condition (Son-Cond) in (8).

\footnotetext{
${ }^{3}$ MA has two types of syllables: $\mathrm{C} ə \mathrm{C}$ and CV syllables. Schwa syllables are the result of a massive vowel reduction in closed syllables (see Bernouss 2007a for more details). We also consider that CVC syllables are the result of the concatenation of the core syllable $\mathrm{CV}$ with the appendix (C).

${ }^{4}$ Dep-IO: Every segment of the output has a correspondent in the input (McCarthy and Prince 1995).
} 
(8) Son-Cond

Schwas are inserted before the most sonorant consonant or between the last two consonants with the same sonority index.

In the case of triliteral sound verbs, the solution for the issue of the directionality of syllabification has been found within the theory of Generalized Alignment, where the constraint Align.R [verb] plays a vital role.

(9) Align-R. [Verb] (Stem, R; Syll, R) (McCarthy and Prince 1993b)

The right edge of the verb's stem is aligned with the right edge of the syllable.

This situation entails that the sonority constraint is ranked below Align- $\mathrm{R}$ when verbs are evaluated. The tableau (the term used in OT to refer to 'table') below shows the ranking of the constraints that is responsible for the generation of sound triliteral verb stems within an Input-Output ${ }^{6}$ model as the base consists of a root (we will take [hrəb] 'to escape' as an example). As illustrated below, Parse, ${ }^{*} \mathrm{P} / \mathrm{C}, \mathrm{N},{ }^{*} \mathrm{Compl}$, and Align-R. are located at the top of the hierarchy as they are not to be violated at any cost; thus, they precede both Dep-IO in the case of epenthesis and $* A p$. in case a stranded consonant is left stranded at the periphery.

(10) Parse, *P/C, N, *Compl, Align-R >> Son-Cond >> DEP-IO >>*Ap

\footnotetext{
${ }^{5}$ The constraint's sensitivity to the lexical category [verb] is necessary as we cannot account for the canonical difference between triliteral verbs and nouns by having recourse to a simple permutation of Align (Stem,R.; Syll, R) and Son-Cond in the hierarchy. Another argument can be brought from English, which has a different stress pattern in nouns and verbs. Nouns are subject to NonFinality, but verbs are not. This could be analyzed with: Align-R(Foot, Verb) >> NonFinality(foot) $>>$ Align-R(Foot, Noun) (John McCarthy personal communication).

${ }^{6}$ Being a Semitic language, MA relies on the root as a unit of lexical organization. The combination of the root and the different affixes into patterns is exploited by the language to derive words with different grammatical meanings (see McCarthy 1979, 1981, among others for details).
} 


\begin{tabular}{|l|l|l|l|l|l|l|l|l|}
\hline$/ \mathrm{drb}^{7} /$ VERB & Parse & $* \mathrm{P} / \mathrm{C}$ & $\mathrm{N}$ & $*$ Compl & $\begin{array}{l}\text { Align-R } \\
\text { [Verb }\end{array}$ & $\begin{array}{l}\text { Son- } \\
\text { Cond }\end{array}$ & Dep-IO & *Ap. \\
\hline 1. hrb & $* !$ & & & & & & & \\
\hline 2. .hrb. & & & $* !$ & & & & & \\
\hline 3. .hrb. & & $* !$ & & & & & & \\
\hline 4. .hər.b. & & & & & $* !$ & & $*$ & $*$ \\
\hline 5. G.h.rəb. & & & & & & $*$ & $*$ & $*$ \\
\hline 6. .hərb. & & & & $* !$ & & & $*$ & \\
\hline 7. .hrəb. & & & & $* !$ & & & $*$ & \\
\hline
\end{tabular}

The basic stem reached through IO correspondence depicts the power of Parse, *P/C, N, *Compl. and Align.R, and the violable character of Son-Cond, Dep-IO and *Ap. This hierarchy results in verbal forms that incorporate phonetic schwas invariably between the last two consonants and display simple onsets and codas (.C.CəC.). Although the form [hər.b] satisfies Son-Cond., it fails to win because of the top rank granted to Align-R.[verb] in the hierarchy.

The lack of an explicit infinitive form in MA compels us to opt for the stem (e.g., [hrəb]) as a form that represents the class of sound triliteral verbs (with which we contrast triliteral nouns) because it acts in an Output-Output model as a base/output to which the paradigms' members should be faithful. This is the form that recurs in the perfective, the imperfective, and the imperative when there are no vowel-initial suffixes. With the presence of vowel-initial suffixes, the schwa moves back to occupy a position before the second root consonant; the cases concern the 3PERS. SG. FEM. form (e.g., [hərbət]) and the 3PERS. PLUR. form (e.g., [hərbu]) of the perfective, the 1, 2 and 3PERs. PLur. forms (e.g., [nhərbu], [thərbu],

\footnotetext{
${ }^{7}$ In OT and more specifically in Correspondence Theory, candidates are accompanied with correspondence relations between elements in related strings S1 and S2 within the framework of the correspondence theory of faithfulness (McCarthy and Prince 1994a.b, 1995, 1999). Correspondence is a relation between segments in a pair of strings; it governs all types of linguistic relations -the S1 and the S2 may be related as an input - output, as a base-reduplicant, or as a pair of output words.
} 
[yhərbu]) of the imperfective, and the 2PERS. FEM., in addition to the 2PERS. PLUR. form (e.g., [hərbi] and [hərbu]) of the imperative. In these cases, any attempt to keep the stem faithful to the base [hrab] will be doomed to failure because of the unviolable character of Onset, a constraint which states that syllables must have onsets: forms like [*hrəb.u] can never be optimal.

As we mentioned above, the structure of nouns is determined by the sonority condition in (8). The tableau below illustrates the derivation of a representative example: [qerd] 'a monkey':

(11) Parse, *P/C, N, *Compl, Son-Cond $>>$ DEP-IO $>>* A p$.

\begin{tabular}{|c|c|c|c|c|c|c|c|}
\hline /qrd/ & Parse & $* \mathrm{P} / \mathrm{C}$ & $\mathrm{N}$ & *Compl & Son-Cond & Dep-IO & *Ap. \\
\hline 1. $\quad$ qrd & *! & & & & & & \\
\hline 2. .qrd. & & & $* !$ & & & & \\
\hline 3. .qrd. & & *! & & & & & \\
\hline 4. .q.rəd. & & & & & $* !$ & $*$ & $*$ \\
\hline 5. qor.d. & & & & & & * & $*$ \\
\hline 6. .qord. & & & & *! & & * & \\
\hline
\end{tabular}

By doing well with respect to the highly ranked constraints like Parse and *Compl, the serious competitor to the actual output [qər.d.] is [q.rəd], with which it shares a violation of DEP-IO and *Ap. This tie at the level of constraint satisfaction is resolved by the constraint Son-Cond, which [q.rəd.] violates since it exhibits a schwa before the less sonorous consonant (sonorant $>$ fricative). Note that nouns build on the form CCəC like [ktəf] 'a shoulder' are similar to $\mathrm{C} \partial \mathrm{CC}$ in derivation.

(12) Parse, *P/C, N, *Compl, Son-Cond $>>$ DEP-IO $>>* A p$. 


\begin{tabular}{|c|c|c|c|c|c|c|c|}
\hline$/ \mathrm{ktf} /$ & Parse & $* \mathrm{P} / \mathrm{C}$ & $\mathrm{N}$ & ${ }^{*}$ Compl & Son-Cond & Dep-IO & *Ap. \\
\hline $\begin{array}{ll}1 . & \mathrm{ktf}\end{array}$ & $* !$ & & & & & & \\
\hline $\begin{array}{ll}2 . & . \mathrm{ktf} .\end{array}$ & & & $* !$ & & & & \\
\hline $\begin{array}{ll}3 . & . \mathrm{kt}\lceil\mathrm{f} .\end{array}$ & & $* !$ & & & & & \\
\hline 4. $. \mathrm{k} . \mathrm{t \partial f}$ & & & & & & * & $*$ \\
\hline 5. $\quad$.kət.f. & & & & & $* !$ & $*$ & $*$ \\
\hline \begin{tabular}{|ll}
6. & .kətf.
\end{tabular} & & & & $* !$ & & * & \\
\hline
\end{tabular}

\section{Alignment and phonological/paradigmatic considerations}

Why is right alignment so vital for the triliteral sound verb? In other words, what is the reason behind the constant violation of the sonority condition by this category of verbs? With the exception of the third person, the perfective paradigm of triliteral sound verbs in (13) shows that the stem is totally identical with the output/base ${ }^{8}[\mathrm{hr}$ b] 'to escape'.

(13) Triliteral sound verbs: [hrəb] 'to escape '

The perfective

$$
\begin{aligned}
& \text { 1PERS . SG. [hrobt] 'I escaped ' 1PERS . PLUR. [hrebna] 'we escaped ' } \\
& \text { 2PERS. SG . [hrəbti] 'you escaped ' 2PERS. PluR. [hrobtu] 'you escaped ' } \\
& \text { 3PERS. SG. MASC. [hrəb] 'he escaped ' 3PERs. Plur. [hərbu] 'they escaped ' } \\
& \text { 3PERS . SG .FEM. [hərbat] /[hərbət] 'she escaped ' }
\end{aligned}
$$

Total faithfulness to the base [hrəb] is violated only when the universal constraint Onset ("syllables must have onsets") is at stake since *[hrəb.u] and *[hrəb-at], where the suffixes $-\mathrm{u}$ and -at are onsetless, are unacceptable.

\footnotetext{
${ }^{8}$ Generally, Correspondence can be seen as a model that may cover relationships ranging from segments, moras, syllables, feet, etc. Research has widened the scope of correspondence from base/reduplicant and IO to circumscriptional phenomena (McCarthy, 2000) to transderivational relations between words (Benua 1995, 1997; Burzio 1996; Kenstowicz 1996; Basri et al. 1998; Kager 1999; Selkirk 1999; etc.).
} 
McCarthy (2005) states that the attested paradigm incorporates verbs like $\int \mathrm{r}$ bb 'to drink' (forms that violate the sonority constraint) because of the ranking of the constraints in (14). Accordingly, the paradigm (15a) emerges as optimal:

*e] $\quad$ *CCC $>$ OP MAX-V SON COND IO MAX-V $>$ IO DEP-V

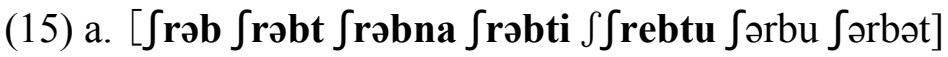

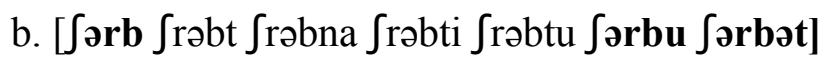

c. $\left[\int\right.$ rəb $\int$ rəbt $\int$ rəbna $\int$ rəbti $\int$ rəbtu $\int$ rəbu $\int$ rəbət $]$

d. [ $\left.\int \partial r b \int \partial r b t \int \partial r b n a \int \partial r b t i \int \partial r b t u \int \partial r b u \int \partial r b \partial t\right]$

For McCarthy (2005), candidates $(15 \mathrm{c}, \mathrm{d})$ have leveled the paradigm to avoid all e/zero

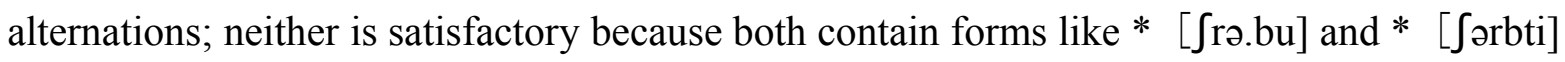
that violate undominated markedness constraints against $ə$ in open syllables and ${ }^{*} \mathrm{CCC}$ (a constraint against triconsonantal clusters). The "phonotactically viable candidates" are (15a,

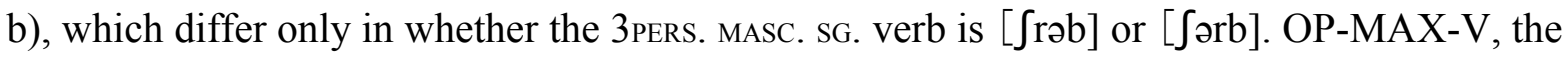
next constraint in the ranking, favors [ $\left.\int \mathrm{r} \partial \mathrm{b}\right]$ because the $\mathrm{CC} \partial \mathrm{C}$ stem pattern is better represented in the rest of the paradigm (Majority-rules effects). Because OP-MAX-V is successful in favoring [ $\int \mathrm{r}$ b $]$ as the verb form, it must dominate the sonority constraint. In our view, this analysis does not provide the basic insight we are looking for. Even McCarthy (2005) admits that the result about majority-rules effects has some intuitive appeal and that it might seem to imply a vote-counting approach to phonology.

In the present analysis, we hold the view that the sonority condition is not satisfied in sound triliteral stems because of the inflectional paradigm of this class of verbs; 
specifically, it is the 1PERS. SG. member that is responsible for this constant violation. If the sonority condition is satisfied, we will have bases like *[hərb] 'escape' instead of [hrəb] ([r] is more sonorant than [b]). Concatenating [hərb], or any verb with a CəCC form, with the 1 PERs. SG. suffix -t (e.g., *[hərbt]) will result in a violation of the constraint *Compl. The only remaining solution is to derive [hərbət] through schwa epenthesis between the last consonant and the suffix; however, this solution results in a paradigmatic problem as the 1PERS. SG. form will become homophonous with the reduced version of the 3 PERS. SG. FEM. one (*[hərbət] "1 PERS. SG. "/[hərbət] "3PERS. SG. FEM.). In other words, the 1PERS. SG. form *[hərbət] will violate the Paradigmatic Contrast constraint (PC) formalized in (16):

(16) $\mathrm{PC}^{9}$

Members of a paradigm must be distinct in form.

In the absence of options, the only solution left is to respect the alignment constraint in (9) in order to freeze the form of the base as $\mathrm{CC} \partial \mathrm{C}$. By doing this, it becomes possible to concatenate the stem with the suffix $-\mathrm{t}([\mathrm{hr}$ b.t $\mathrm{t}$ satisfies $*$ Compl. by violating the constraint *Ap., a constraint ranked very low in the hierarchy), and to avoid the form *[hərbət], which is similar to the 3PERS. SG. FEM. form. In other words, violating sonority gives the 1 PERS. SG. form the chance to respect $*$ Compl. and maximizes paradigmatic contrast in the perfective as paradigms favor members that are formally distinct. A look at derivation of the form [hrəbt] 'I escaped' will clarify the matter:

\footnotetext{
${ }^{9}$ This notion of contrast within a paradigm has been formalized by Crosswhite (1999) and an Anti-Ident constraint has been introduced. Similarly, for Alderete (1999), in addition to markedness and faithfulness constraints, Universal Grammar contains a set of antifaithfulness constraints that evaluate pairs of morphologically related words and require a phonological difference between them. On another scale, Kenstowicz (2005) proposes an analysis where he formulated a Paradigmatic Contrast constraint, which ensures that two phonologically distinct members of a paradigm must remain phonetically distinct.
} 
(17) PC $>>*$ Compl. $>>$ Align-R. [verb] $>>$ Son-Cond

\begin{tabular}{|l|c|c|c|c|}
\hline $\begin{array}{l}\text { /hrb-t/ } \\
{[\text { hrəb }]}\end{array}$ & PC & ${ }^{*}$ Compl. & $\begin{array}{c}\text { Align-R. } \\
\text { [verb] }\end{array}$ & Son-Cond \\
\hline $1 . \bullet$ hrəb.t & & $* !$ & & $*$ \\
\hline 2. hərb.t & & & & \\
\hline 3. hərbət & $* !$ & & $*$ & \\
\hline
\end{tabular}

The tableau shows that total faithfulness to a base which does not satisfy sonority is necessary as any attempt to respect the sonority condition will either lead to a violation of the powerful *Compl. or trigger the optimization of a form that would create a paradigmatic problem since paradigms prefer to have members that are phonetically different ${ }^{10}$.

As far as the structure of the whole perfective paradigm is concerned, five of its members are faithful to the base (i.e., they satisfy right alignment) and two members are not (the 3PERS. SG. FEM. and the 3PERs. PLUR. forms). In this last case, total faithfulness to the base is impossible because of the high rank accorded to the universal constraint Onset. The vowelinitial suffixes -ot/-at (the 3PERs. SG. FEM. markers) and the suffixal vowel -u (the 3PERS. PLUR.

\footnotetext{
${ }^{10}$ The ranking in (17) leads to the desired results without having recourse to the identity constraint Anchor (McCarthy 2000), which stipulates that any element at the designated periphery of the base/output has a correspondent at the designated periphery of the output.
} 
marker), which need onsets, cannot be concatenated with the base without leading to a violation of Align-R.[verb]. The next tableau displays [hərbu] ' they escaped' as an example. (18) Onset $>>$ Align-R. [verb] $>>*$ Ap.

\begin{tabular}{|l|c|c|c|}
\hline $\begin{array}{l}\text { /h rb-u/ } \\
{[\text { hrob] }}\end{array}$ & Onset & $\begin{array}{l}\text { Align-R. } \\
\text { [verb] }\end{array}$ & $*$ Ap \\
\hline 1. hər.bu & & $*$ & \\
\hline 2. h.rəb.u & $* !$ & & $*$ \\
\hline 3. h.rə.bu & & $*$ & $* !$ \\
\hline
\end{tabular}

Whereas the 1PERS. SG. form satisfies right alignment for phonological and paradigmatic reasons, the 1PERS. PLUR. and the 2PERS. (SG. \& PLUR.) forms of the paradigm (14) could be optimized as $\mathrm{C} ə \mathrm{CC}+$ suffix; forms like [hərbna], [hərbti], [hərbtu] that satisfy the sonority condition can be acceptable in MA. However, the derivation of these forms as $\mathrm{CC} \curvearrowright \mathrm{C}+$ suffix has a different paradigmatic motivation since they sacrifice sonority satisfaction in order to keep the paradigm uniform; in other words, these forms are simply attracted to the 1PERS. SG. form in order to achieve paradigmatic leveling. ${ }^{11}$ To sum up, the paradigm we have investigated raises important questions related to the influence of paradigmatic organization on morpho-phonological derivation. This influence, which may lead to either contrast or uniformity between paradigms members, shows that it is possible to talk about the uniformity of the base and intraparadigmatic influence at the same time.

\section{Conclusion}

The issue we have approached shows that the violation of the sonority condition by triliteral verbs is phonologically and paradigmatically motivated. This article has also been an attempt and an invitation to consider a poorly studied aspect of morphophonology, namely the impact

11 Further evidence to back up the status of the attractor accorded to the 1PERs. SG. form can be brought from the class of geminated and concave verbs where the 1 PERS. PLUR. and the 2 PERS. (SG. \& PLUR.) are also attracted to the 1 PERS. SG. form in order to reach paradigmatic leveling. 
of paradigms on normal phonology. A crucial task for future research is to develop appropriate analytic tools and grammatical formalisms that allow phenomena such as contrast and uniformity to be systematically studied and the resultant generalizations to be adequately expressed.

\section{Abbreviations}

PERS.: person. SG.: singular. PLUR.: plural. FEM.: feminine. MASC.: masculine.
\end{abstract}

\title{
References
}

Alderete, John. 1999. Dominance effects as transderivational anti-faithfulness. Phonology 18:201-53.

Al Ghadi, Abdellatif.1990. Moroccan Arabic plurals and the organization of the Lexicon. Doctoral dissertation, Mohammed V University, Rabat, Morocco.

Basri, Hassan, Ellen Broselow, Daniel Finer, and Elisabeth Selkirk. 1998. Morphologically grounded affix classes: The case of Makassarese. Ms., State University of New York at Stony Brook, NY and University of Massachusetts at Amherst, MA

Benhallam, Abderrafi. 1990. Moroccan Arabic syllable structure. In Langues et Littératures VIII:177-191.Faculty of Letters: Rabat, Morocco.

Bennis, Said. 1992. La formation du causatif en Arabe Marocain. Doctoral dissertation, Mohammed V University, Rabat, Morocco.

Benua, Laura. 1995. Identity effect in morphological truncation. In University of Massachusetts occasional papers in linguistics: Papers in Optimality Theory, ed. Jill Beckman, Laura Walsh Dicky and Suzanne Urbanczyk, 77-136. Amherst, MA: GLSA publications. 
Benua, Laura. 1997. Transderivational identity: Phonological relations between words. Doctoral dissertation, University of Massachusetts, Amherst.

Bernouss, M. Rida. 2007a. A moraic approach to syllables: Evidence from Moroccan Arabic. Iranian Journal of Language Studies 1(3):155-169.

Bernouss, M. Rida. 2007b. Moroccan Arabic syllable structure. Lingua et Linguistica 1(1):91-106.

Boudlal, Abdelaziz. 2001. Constraint interaction in the phonology and morphology of Casablanca Moroccan Arabic. Doctoral dissertation, Mohammed V University, Rabat, Morocco.

Burzio, Luigi. 1996. Surface constraints vs. underlying representations. In Current trends in phonology: Models and methods, ed. Jacques Durand and Bernard Laks, 123-42. European Studies Research Institute and University of Salford.

Crosswhite, Katherine. 1999. Intra-paradigmatic homophony avoidance in two dialects of Slavic. Ms., UCLA.

Harrell, Richard. 1962. A Short reference grammar of Moroccan Arabic. Washington, DC: Georgetown University Press.

Kager, René. 1999b. Surface opacity of metrical structure in Optimality Theory. In The derivational residue in phonological Optimality Theory, ed. B. Hermans and M. van Oostendorp, 207-45. Amesterdam: John Benjamin.

Kenstowicz, Michael. 1996. Base-Identity and Uniform Exponence: Alternatives to Cyclicity. In Current trends in phonology: Models and methods, ed. Jacques Durand and Bernard Laks, 363-94.Manchester, England: European Studies Research Institute, University of Salford. 
Kenstowicz, Michael. 2005. Paradigmatic uniformity and contrast. In Paradigms in phonological theory, ed. Laura Downing, Tracy Alan Hall, and Renate Raffelsiefen, 145-69. Oxford: Oxford University Press.

McCarthy, John J. 1979. Formal problems in Semitic phonology and morphology. Doctoral dissertation, MIT, Cambridge, MA.

McCarthy, John J. 1981. A Prosodic theory of nonconcatenative morphology. Linguistic Inquiry 12:373-418.

McCarthy, John J. 2000. Faithfulness and prosodic circumscription. In Optimality Theory: Syntax, phonology, and acquisition, ed. Joost. Dekkers, Frank. van der Leeuw and Jeroen. van de Weijer,151-181. Oxford: Oxford University Press.

McCarthy, John J. 2005. Optimal paradigms. In Paradigms in phonological theory, ed. Laura Downing, Tracy Alan Hall, and Renate Raffelsiefen, 170- 210. Oxford: Oxford University Press.

McCarthy, John J., and Alan Prince. 1993a. Prosodic morphology I: Constraint interaction and satisfaction. New Brunswick, NJ: Rutgers University Center for Cognitive Science.

McCarthy, John J., and Alan Prince. 1993b. Generalized alignment. In Yearbook of Morphology, ed.Geert Booij and Jaap van Marle, 79-153. Dordrecht: Kluwer.

McCarthy, John J., and Alan Prince. 1994a. The emergence of the unmarked: Optimality in prosodic morphology. In Proceedings of the NELS 24, 333-379. Amherst: GLSA publications.

McCarthy, John J., and Alan Prince. 1994b. An overview of prosodic morphology. Lectures presented at the OTS/HIL workshop on prosodic morphology, University of Utrecht. 
McCarthy, John J. and Alan Prince. 1995. Faithfulness and reduplicative identity. In University of Massachusetts occasional papers in linguistics18, ed. Jill.

Beckman, Laura Walsh Dickey and Suzanne Urbanczyk , 249-384. Amherst, MA: GLSA.Publications.

McCarthy, John J., and Alan Prince. 1999. Faithfulness and identity in prosodic morphology. In The prosody-morphology interface, ed. René Kager, Harry van der Hulst, and Wim Zooneveld , 218-309. Cambridge: M.I.T.

Prince, Alan and Paul Smolensky. 1993. Optimality Theory: Constraint Interaction in generative grammar. Rutgers University and University of Colorado at Boulders .

Selkirk, Elizabeth. 1999. Morphologically governed output-output constraints in a noncyclic Optimality theoretic grammar: Evidence from the Makassar languages. Paper presented at Sophia University, Tokyo.

Sherer, Tim. 1994. Prosodic Phonotactics. Doctoral dissertation, University of Massachusetts, Amherst. 